\title{
The Australian brushtail possum (Trichosurus vulpecula) gonadotrophin $\alpha$-subunit: analysis of cDNA sequence and pattern of expression
}

\author{
A E Fidler, S B Lawrence, D M Vanmontfort, D J Tisdall and \\ K P McNatty
}

\author{
AgResearch Wallaceville, PO Box 40063, Upper Hutt, New Zealand \\ (Requests for offprints should be addressed to A E Fidler)
}

\begin{abstract}
A cDNA sequence from the gonadotrophin $\alpha$-subunit mRNA of Australian brushtail possum (Trichosurus vulpecula) has been determined and analysed. Comparison with seven eutherian mammalian gonadotrophin $\alpha$-subunit gene sequences revealed an average of $82.6 \%$ homology between the coding region nucleotide sequences and $88.8 \%$ identity between the predicted amino acid sequences. The predicted possum gonadotrophin $\alpha$-subunit protein has ten evolutionarily conserved cysteine residues, two potential $N$-linked glycosylation sites and a putative enzyme recognition sequence which it has been suggested is required for sulphation of carbohydrate moieties. Comparison of the possum gonadotrophin $\alpha$-subunit $3^{\prime}$ untranslated region (UTR) sequence with the $3^{\prime}$ UTRs of
\end{abstract}

eutherian $\alpha$-subunit transcripts revealed sequence homology. In particular, an 18 nucleotide imperfect palindromic sequence present in the possum $3^{\prime}$ UTR, with the potential to form a hairpin loop, was found to be evolutionarily conserved and present in five out of seven eutherian $\alpha$-subunit $3^{\prime}$ UTR sequences. In situ hybridization localized the transcripts to a sub-population of anterior pituitary cells presumed to be gonadotrophs and thyrotrophs. In summary, these results indicate considerable conservation of the structure and function of the gonadotrophin $\alpha$-subunit protein since the divergence of the marsupial and eutherian mammalian lineages.

Fournal of Molecular Endocrinology (1998) 20, 345-353

\section{INTRODUCTION}

The mammalian subclass Marsupialia comprises a diverse fauna whose evolutionary lineage parallels that of the eutherian (placental) mammals from which it branched some 130 million years ago (Janke et al. 1997). Marsupial and eutherian mammals are distinguished principally by their differing reproductive strategies. In contrast to the extended period of intrauterine development characteristic of eutherian mammals, marsupials give birth to altricial young at a comparatively early stage of development. This 'early' birth is then followed by an lengthy lactation period during which the marsupial young are protected in a maternal abdominal pouch (Low 1978, Tyndale-Biscoe \& Janssens 1988).

In recent years, increased interest in marsupial reproductive biology has arisen from both ecological and economic concerns; in Australia from a wish to conserve endangered native species, and in New Zealand from a need to reduce the population of the introduced brushtail possum (Trichosurus vulpecula), which damages native forests and acts as a feral reservoir for bovine tuberculosis (Burbidge \& McKenzie 1989, Cowan 1996, Cowan \& Tyndale-Biscoe 1997).

In mammals, the two gonadotrophic hormones secreted from the anterior pituitary, namely folliclestimulating hormone (FSH) and luteinizing hormone (LH), are required for ovarian follicle maturation and oocyte release in females, and spermatogenesis in males (Hseuh et al. 1989, Richards 1994, Kendall et al. 1995, Kumar et al. 1997). In addition, gonadotrophins stimulate gonadal steroidogenesis and participate in regulating the mammalian ovarian cycle (Richards 1994). The gonadotrophins act by binding to specific membrane-bound receptors, activating second messenger pathways, and thereby influencing the 
physiology of the target cell (Richards 1994). Structurally, both FSH and LH are heterodimers of two dissimilar, non-covalently associated glycoproteins. The $\alpha$-subunit is common to both FSH and LH and to an additional pituitary hormone, thyroid-stimulating hormone (TSH), while the $\beta$-subunit is hormone specific and determines receptor binding specificity (Ryan et al. 1987, Combarnous 1992, Nagaya \& Jameson 1994).

Sequence information, both nucleotide and amino acid, is available for the gonadotrophins of a wide range of vertebrates (Combarnous 1992). However, comparatively little is known about the structure and function of marsupial gonadotrophins (Moore et al. 1997). Such information is needed to guide the development of biological control strategies based on perturbing possum reproductive endocrine function and, in addition, may provide insights into the evolution of the marsupial and eutherian reproductive systems. The cDNA sequence and pattern of gonadotrophin $\alpha$-subunit gene expression in the brushtail possum pituitary is reported here.

\section{MATERIALS AND METHODS}

\section{Reverse transcriptase-polymerase chain reaction (RT-PCR)}

Pituitaries were collected from euthanased possums and stored at $-70{ }^{\circ} \mathrm{C}$. Total RNA was extracted from the pituitary tissue using guanidine isothiocyanate-phenol (Chomczynski \& Saachi 1987; TRIzol reagent, Gibco BRL, Grand Island, NY, USA) and oligo(dT)-primed first strand cDNA synthesized using reverse transcriptase (Superscript II, Gibco-BRL). PCR primers were designed from conserved nucleotide sequences identified by comparison of published eutherian gonadotrophin $\alpha$-subunit cDNA sequences (human (Fiddes \& Goodman 1979), mouse (Chin et al. 1981), rat (Godine et al. 1982), bovine (Erwin et al. 1983, Nilson et al. 1983), porcine (Hirai et al. 1989), ovine (Bello et al. 1989)): forward primer 5'ATGGATTACTACAGAAAATATGCAGCTG TC-3', reverse primer 5'-TCCCATCACTGTG GCCTTGGTAAATGCTTTGGCCACACAG-3'. An amplification product of the predicted size (299 bp) was produced using the following PCR conditions: $94^{\circ} \mathrm{C}, 1 \mathrm{~min}$, one cycle; $94{ }^{\circ} \mathrm{C}, 30 \mathrm{~s}$, $45{ }^{\circ} \mathrm{C}, 30 \mathrm{~s}, 72{ }^{\circ} \mathrm{C}, 30 \mathrm{~s}, 35$ cycles; $72{ }^{\circ} \mathrm{C}, 10 \mathrm{~min}$, one cycle. The identity of the PCR product was determined by DNA sequencing, and gene specific primers (GSPs) were designed for both $3^{\prime}$ and $5^{\prime}$ RACE (rapid amplification of cDNA ends) (Frohman et al. 1988). A single 3' RACE GSP (5' - CTGCATATTTTTCACTCCTTCCCAGAT
GGGGAGT-3') produced a specific amplification product of $0.6 \mathrm{~kb}$. The $5^{\prime} \mathrm{RACE}$ required three nested GSPs (GSP1 5'-TACATTGGCAAATG GGAGCT-3'; GSP2 5'-TGTTCTCCTTCAGC TTGCGTTCTG-3'; GSP3 5' CATAATAAACA CCCCATGTGG-3') to produce a specific amplification product of $0.2 \mathrm{~kb}$. The PCR conditions used for the RACE reactions were as specified by the manufacturer (Gibco BRL).

\section{Cloning and sequencing}

PCR amplification products were electrophoresed through $1 \%(\mathrm{w} / \mathrm{v})$ low melting point agarose gels (SeaPlaque $^{\text {GTG }}$, FMC BioProducts, Rockland, ME, USA). Amplification products of the anticipated size were cut from the gel, ligated into the T-tailed cloning vector pMOS-Blue (Amersham, Amersham, Bucks, UK) and transformed into competent E. coli DH5a cells (Hanahan 1985). Plasmids having inserts were first identified by restriction enzyme digestion, purified for DNA sequencing by alkaline lysis (Boehringer Mannheim, Mannheim, Germany) and sequenced using an ABI 373 DNA sequencer (Applied Biosystems, Foster City, CA, USA). All enzymes were used according to manufacturer specifications (Boehringer Mannheim). Sequence changes due to Taq DNA polymerase-catalysed replication errors were identified by comparison of sequences from a minimum of three independent PCRs. Nucleotide sequences common to at least two clones from independent PCRs were considered correct because of the low probability of Taq DNA polymerase introducing identical alterations at the same nucleotide position in two independent PCR amplifications.

\section{In situ hybridization}

The in situ hybridization methodology has been described previously (Tisdall et al. 1994). The cDNA sequence to be used as a probe was amplified by RT-PCR from possum pituitary cDNA and cloned into pGem3Z (Promega, Madison, WI, USA). Radioactively labelled $\left(\left[\alpha-{ }^{33} \mathrm{P}\right]\right.$ uridine triphosphate) sense and antisense RNA transcripts were synthesized from linearized plasmid templates using SP6 or T7 RNA polymerase (Promega). Paraformaldehyde-fixed, paraffin wax-embedded possum pituitary tissue sections $(5 \mu \mathrm{m})$ were cut and transferred to Superfrost-Plus glass slides (Erie Scientific, Portsmouth, NH, USA). The sections were deparaffinized in xylene and hydrated through an alcohol series to water. Sections were immersed in $0.2 \mathrm{M} \mathrm{HCl}$ (20 min, room temperature) and 
washed in $2 \times \mathrm{SSC}$ for $30 \mathrm{~min}$. The sections were digested with proteinase $\mathrm{K}(2 \mu \mathrm{g} / \mathrm{ml}$, Boehringer Mannheim) at $37^{\circ} \mathrm{C}$ for $10 \mathrm{~min}$, acetylated in $0.1 \mathrm{M}$ triethanolamine, $\mathrm{pH} 8 \cdot 0,0 \cdot 25 \%(\mathrm{v} / \mathrm{v})$ acetic anhydride (twice for $5 \mathrm{~min}$, room temperature) and then washed in $2 \times \mathrm{SSC}$ before dehydration through an alcohol series to absolute ethanol. Hybridization was performed in $50 \%(\mathrm{w} / \mathrm{v})$ formamide, $0.3 \mathrm{M}$ $\mathrm{NaCl}, 10 \mathrm{mM}$ Tris- $\mathrm{HCl}, \mathrm{pH} 6 \cdot 8,10 \mathrm{mM}$ sodium phosphate, $\mathrm{pH} \quad 6 \cdot 8,5 \mathrm{mM}$ EDTA, $\mathrm{pH} \quad 8 \cdot 0$, $1 \times$ Denhardt's solution $(0 \cdot 02 \%(\mathrm{w} / \mathrm{v})$ each of BSA, Ficoll and polyvinyl pyrrolidone), $10 \%(\mathrm{w} / \mathrm{v})$ dextran sulphate, $50 \mathrm{mM}$ dithiothreitol, $1 \mathrm{mg} / \mathrm{ml}$ tRNA and approximately $2 \times 10^{5}$ c.p.m. $/ \mu l{ }^{33} \mathrm{P}$ labelled sense or antisense riboprobe at $55^{\circ} \mathrm{C}$ for $18 \mathrm{~h}$. Following hybridization the slides were washed sequentially in $5 \times \mathrm{SSC}\left(50^{\circ} \mathrm{C}, 15 \mathrm{~min}\right.$, twice); $2 \times \mathrm{SSC} / 50 \%$ (v/v) formamide $\left(65^{\circ} \mathrm{C}\right.$, $15 \mathrm{~min}$, twice) and $2 \times \mathrm{SSC}\left(37^{\circ} \mathrm{C}, 5 \mathrm{~min}\right.$, four times). The sections were incubated with RNase A (Boehringer Mannheim; $20 \mu \mathrm{g} / \mathrm{ml}$ in $0.4 \mathrm{M} \mathrm{NaCl}$, $10 \mathrm{mM}$ Tris- $\mathrm{HCl}, \mathrm{pH} 7 \cdot 5,5 \mathrm{mM}$ EDTA) at $37^{\circ} \mathrm{C}$ for $30 \mathrm{~min}$ and then sequentially washed in $2 \times \mathrm{SSC} / 50 \% \quad(\mathrm{v} / \mathrm{v})$ formamide $\left(65^{\circ} \mathrm{C}, 15 \mathrm{~min}\right.$, twice), $2 \times \mathrm{SSC}\left(37^{\circ} \mathrm{C}, 15 \mathrm{~min}\right)$ and $0.2 \times \mathrm{SSC}$ $\left(37^{\circ} \mathrm{C}, 15 \mathrm{~min}\right)$. The slides were dehydrated through an alcohol series, air-dried, coated with LM-1 emulsion (Amersham) and exposed at $4{ }^{\circ} \mathrm{C}$ for 8 days. The emulsion was developed and the sections stained with haematoxylin and viewed using light and dark field illumination on a Olympus BH-2 microscope. Hybridization of duplicate sections with a ${ }^{33} \mathrm{P}$-labelled sense riboprobe was used as a negative control.

\section{RESULTS}

The possum gonadotrophin $\alpha$-subunit cDNA nucleotide sequence, and corresponding predicted amino acid sequence, are shown in Fig. 1. Determination of the cDNA sequence identity was by comparison with published eutherian gonadotrophin $\alpha$-subunit gene sequences and comparison of the predicted amino acid sequence with $N$-terminal sequence obtained from purified possum gonadotrophin $\alpha$-subunit (Moore et al. 1997). All sequence data shown were derived from a minimum of three clones derived from separate amplification reactions to allow for sequence alterations that may have been introduced during Taq DNA polymerase catalysed amplification reactions.

The cDNA sequence, including the polyA tail, was found to be 756 nucleotides in length and contained a 363 nucleotide open reading frame (positions 118-480) which encoded the 120 amino acid $\alpha$-subunit precursor protein. The length of the gonadotrophin $\alpha$-subunit gene transcript in adult possum pituitary, as determined by Northern hybridization, was approximately $0.7 \mathrm{~kb}$ (data not shown), confirming that the majority of the $\alpha$-subunit mRNA sequence has been obtained. The boundary between the 24 amino acid signal and 96 amino acid mature protein sequences was determined by comparison of the predicted precursor protein sequence with 11 residues of $N$-terminal sequence from purified possum gonadotrophin $\alpha$-subunit, with which there was complete sequence identity (Moore et al. 1997). As partial $N$-terminal degradation may have occurred during the $\alpha$-subunit purification, the signal peptide/mature protein boundary assignment was confirmed by comparison with eutherian mammal gonadotrophin $\alpha$-subunit homologues (Fig. 2). The mature protein had two potential $N$-linked glycosylation sites (sequence motif Asn-Xxx-Ser/Thr; Pless \& Lennarz 1977) at residues asparagine +56 and +82 and ten evolutionarily conserved cysteine residues $(+11,+14,+32$, $+35,+36,+63,+64,+86,+88,+91$ ) (Fig. 1) (Pierce $\&$ Parsons 1981). Figure 2 shows a comparison of the possum $\alpha$-subunit protein with its eutherian homologues using the conserved cysteine residues for alignment. Quantitative comparisons of the possum $\alpha$-subunit cDNA nucleotide and predicted amino acid sequences with seven eutherian $\alpha$-subunit sequences (human, mouse, rat, bovine, porcine, ovine and donkey) revealed mean homologies of $82.6 \%$ (coding region nucleotide sequence), $88 \cdot 8 \%$ (precursor protein) and $89 \cdot 7 \%$ (mature protein).

Nucleotide sequence homology between the possum and eutherian transcripts extended outside the coding region. In particular the possum $3^{\prime}$ untranslated region ( $3^{\prime}$ UTR) sequence 610724 showed a high level of homology with a segment of the $3^{\prime}$ UTRs of ovine $(71 \cdot 3 \%)$, bovine $(70 \cdot 4 \%)$, porcine $(69 \cdot 6 \%)$ and horse $(69 \cdot 0 \%) \alpha$-subunit cDNA sequences, with a maximum of two nucleotide insertions being required to gain alignment. Within this conserved region were two overlapping imperfect palindromic sequences 5'-TCTTTTCA TTTGAAATGA-3' (nucleotides 658-675) and 5''TTTTCATTTGAAATGAAAA-3' (nucleotides 660-678). Alignment of the possum, ovine, human, bovine, porcine and horse $\alpha$-subunit $3^{\prime}$ UTR sequences indicated partial evolutionary conservation of these imperfect palindromic sequences (Fig. 3). Another feature present in the possum 3' UTR, located approximately eight nucleotides $3^{\prime}$ to the imperfect palindromes, was an 'AU-rich' sequence, 5'-AUUUA-3' (nucleotides 684-688), which also appeared to be evolutionarily conserved (Fig. 3). 


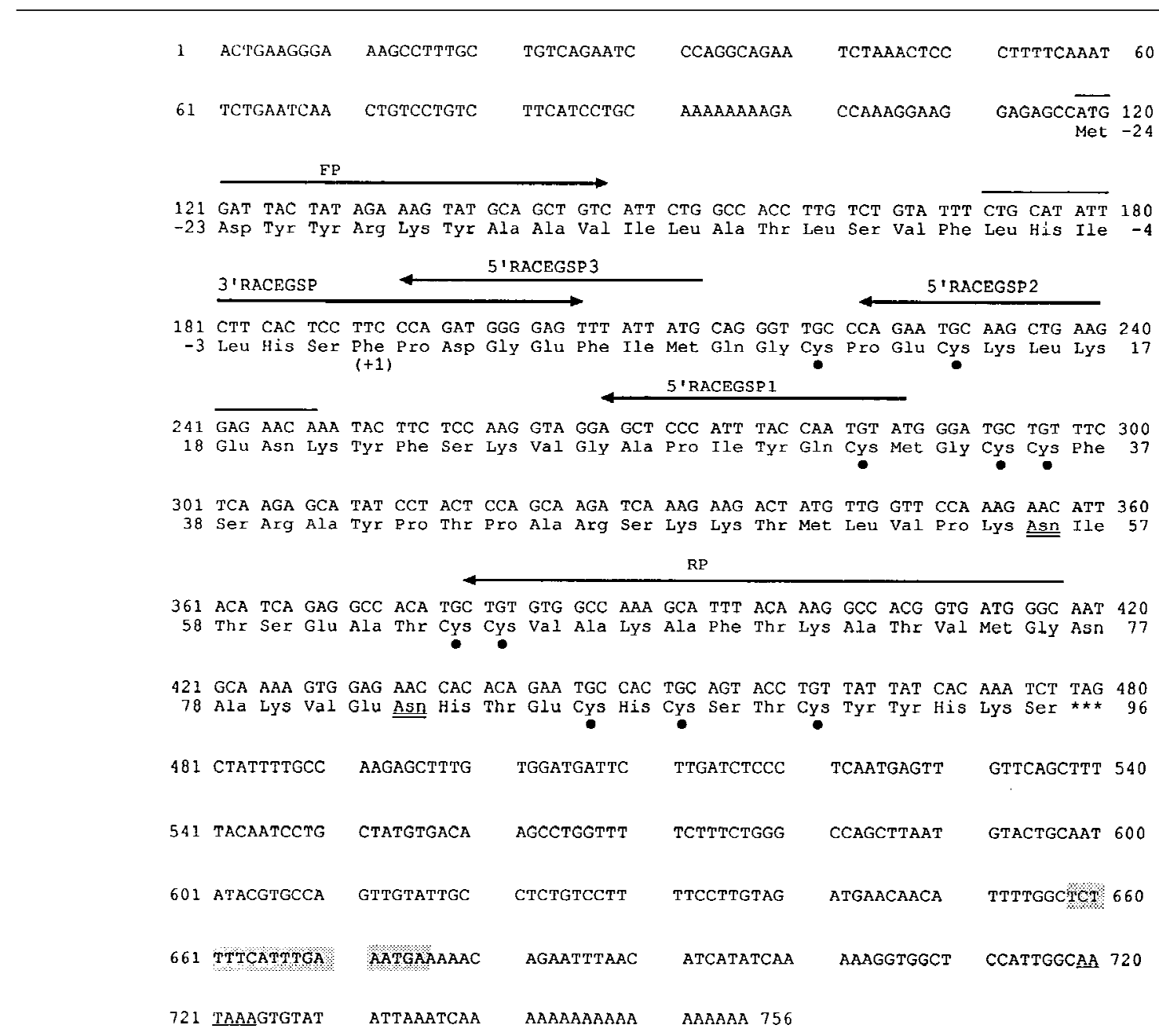

FIGURE 1. The cDNA and predicted protein amino acid sequences of the possum gonadotrophin $\alpha$-subunit gene. Coding and signal sequences were identified by homology with eutherian mammal $\alpha$-subunit sequences and confirmed by $N$-terminal sequencing of purified possum FSH $\alpha$-subunit protein. Potential $N$-linked glycosylation sites (Asn-X-Thr/Ser; Pless \& Lennarz 1977) are double-underlined $($ Asn +56, Asn +82$)$ and ten cysteine residues in the mature protein (residues $+11,+14,+32,+35,+36,+63,+64,+86,+88$ and +91 ) are marked $(\bigcirc)$. A consensus polyadenylation sequence (AATAAA, nucleotides 719-724) is single-underlined. An eighteen nucleotide sequence that may form a hairpin loop (nucleotides 658-675) is shaded. The $N$-terminal amino acid of the mature protein is indicated, Phe $(+1)$, as is the termination codon $(\star \star \star)$. The locations of the PCR primers used are indicated by heavy lines above the sequence with an arrow-head denoting the 3 '-terminus. Abbreviations: FP, forward primer; RP, reverse primer; 3' RACE GSP, 3' RACE gene specific primer; 5' RACE GSP1, first 5' RACE gene specific primer; 5' RACE GSP2, second (nested) 5' RACE gene specific primer; 5' RACE GSP3, third (nested) 5' RACE gene specific primer. (GenBank Accession No. AF004520.)

In situ hybridization of adult possum pituitary sections with $\alpha$-subunit antisense riboprobes produced a punctate pattern of expression with a sub-population of cells within the anterior pituitary showing high levels of gene expression (Fig. 4). The $\alpha$-subunit-expressing cells appeared unevenly distributed through the anterior pituitary with a higher density consistently found towards the peripheral layers (Fig. 4C and D). No $\alpha$-subunit mRNA was detected in the posterior pituitary. Hybridization with a sense (negative control) riboprobe consistently produced a very low density of randomly distributed silver grains, indicating no specific hybridization (not shown).

\section{DISCUSSION}

A surprising finding arising from the quantitative comparisons of the possum and eutherian $\alpha$-subunit 


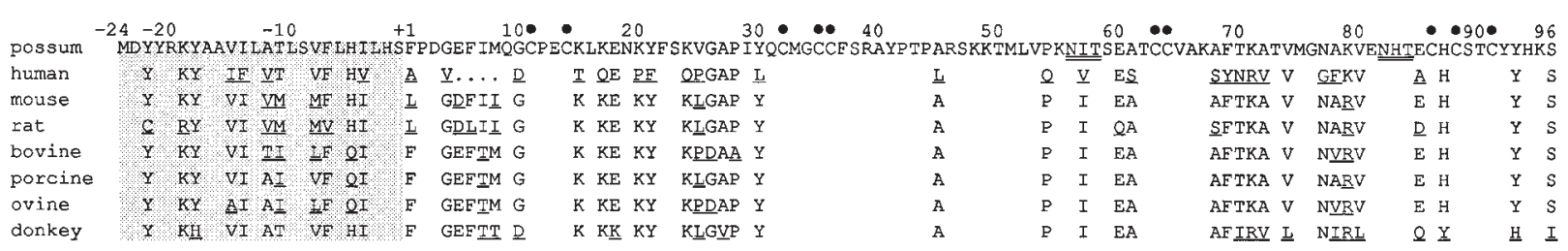

FIGURE 2. Alignment of the possum gonadotrophin $\alpha$-subunit amino acid sequence with homologues from seven eutherian mammals (human (Fiddes \& Goodman 1979), mouse (Chin et al. 1981), rat (Godine et al. 1982), bovine (Erwin et al. 1983, Nilson et al. 1983), porcine (Hirai et al. 1989), ovine (Bello et al. 1989), donkey (Chopineau \& Stewart 1996)). Positions at which all the sequences are identical are indicated by spaces. Where one or more of the eutherian sequences differs from the possum sequence the differing amino acid is underlined. A four space insertion, indicated by ...., is included to align the 116 amino acid human sequence with the other mammalian sequences. The positions of conserved cysteine residues $(-)$ and potential $N$-linked glycosylation sites (double-underlined) are indicated. Signal sequences are shaded. All the amino acid sequences shown are derived from the cDNA sequences referenced.

sequences was that the mean percentage identity of seven eutherian $\alpha$-subunit mature protein sequences (human, mouse, rat, bovine, porcine, ovine, donkey) compared amongst themselves, $84.9 \%$, was lower than that from the eutherian versus possum comparison, $89 \cdot 7 \%$. This differential was still present if the human sequence was omitted from the comparison, with the mean sequence identity of the eutherian mature proteins being $90 \cdot 2 \%$ and the mean sequence identity of the eutherian and possum sequences $92 \cdot 4 \%$. Thus there appear to have been strongly conservative selection pressures acting on the gonadotrophin $\alpha$-subunit gene during the 130 million years separating the marsupial and eutherian lineages. Presumably the requirement that the gonadotrophin $\alpha$-subunit must interact appropriately with three different $\beta$-subunits (FSH $\beta$, LH $\beta$, TSH $\beta$ ), and with the corresponding receptors, placed considerable restrictions on viable sequence changes (Combarnous 1992).

The evolutionary sequence conservation was not evenly distributed through the gonadotrophin $\alpha$-subunit. In particular residues +31 to +67 showed considerable conservation, wherein the only differences from the possum sequence are in the human (four amino acid differences) and rat (single difference) protein sequences. The remaining five eutherian gonadotrophin $\alpha$-subunit sequences (mouse, bovine, porcine, ovine and donkey) were identical within this region. Included within this highly conserved region was one of two evolutionarily conserved potential $N$-linked glycosylation sites, Asn $(+56)$, the other being Asn $(+82)$, and the peptide sequence Pro-(Leu or Ala)-Arg-Ser-Lys-Lys (+44 to +49 ) which is thought to be required for sulphation of $N$-linked carbohydrate moieties (Mengeling

\begin{tabular}{|c|c|c|c|c|c|}
\hline possum & $\mathrm{UAG}_{480}$ & $-(\mathrm{N})_{173^{-}}$ & 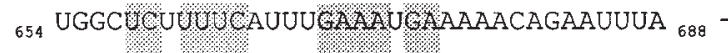 & $-(\mathrm{N})_{30}-\mathrm{AAUAAA}$ & $-(N)$ \\
\hline ovine & $\mathrm{UAA}_{433}$ & $-(\mathrm{N})_{182^{-}}$ & 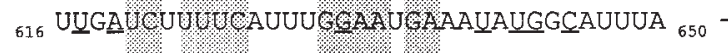 & $-(\mathrm{N})_{30}$-AAUAAA & $-(N)$ \\
\hline human & $\mathrm{UAA}_{401}$ & $-(N)_{182}^{-}$ & 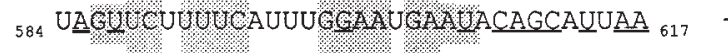 & $-(\mathrm{N})_{15}-\mathrm{AAUAAA}$ & $-(\mathrm{N})$ \\
\hline bovine & $\mathrm{UAA}_{440}$ & $-(N)_{182}-$ & AUUUGG2 NUGAAAUAUGGCAAUUUA ${ }_{657}$ & $-(\mathrm{N})_{30}-\mathrm{AAUAAA}$ & $-(\mathrm{N})$ \\
\hline porcine & $\mathrm{UAA}_{445}$ & $-(N)_{184}-$ & ${ }_{630}$ UCGCUCUUUUCAUUUGGA-CGAAAUGCAGCAUUUA ${ }_{664}$ & $(\mathrm{~N})_{28}-\mathrm{AAUAAA}$ & $-(N)$ \\
\hline horse & $\mathrm{JAA}_{311}$ & $-(\mathrm{N})_{182^{-}}$ & 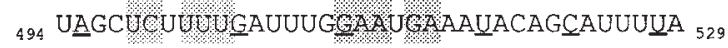 & ${ }_{9}-(\mathrm{N})_{30}-\mathrm{AAUAAA}$ & $-(N)$ \\
\hline
\end{tabular}

FIGURE 3. Comparison of the 3' UTR sequences of six mammalian gonadotrophin $\alpha$-subunit mRNAs. The nucleotide numbering shown is from the following references: possum (this work), ovine (Bello et al. 1989), bovine (Erwin et al. 1983), porcine (Hirai et al. 1989), horse (Stewart et al. 1987). The human sequence is a composite, with the sequences in normal type from Fiddes \& Goodman (1979) (cDNA sequence) and nucleotides in bold type from exon 4 of the genomic sequence (Fiddes \& Goodman 1981). The donkey gonadotrophin $\alpha$-subunit sequence has not been included as insufficient 3' UTR sequence has been reported (Chopineau \& Stewart 1996). Nucleotides proposed to form the stem portion of a potential hairpin loop are shaded and nucleotides differing from the possum sequence are underlined. An 'AU-rich' (i.e. AUUUA) sequence is present 7-8 bases 3 ' to the potential hairpin sequence. Translation termination codons (UAG and UAA) are shown at the $5^{\prime}$ end of the $3^{\prime}$ UTR sequences and polyadenylation sequences (AAUAAA) at the $3^{\prime}$ end. 

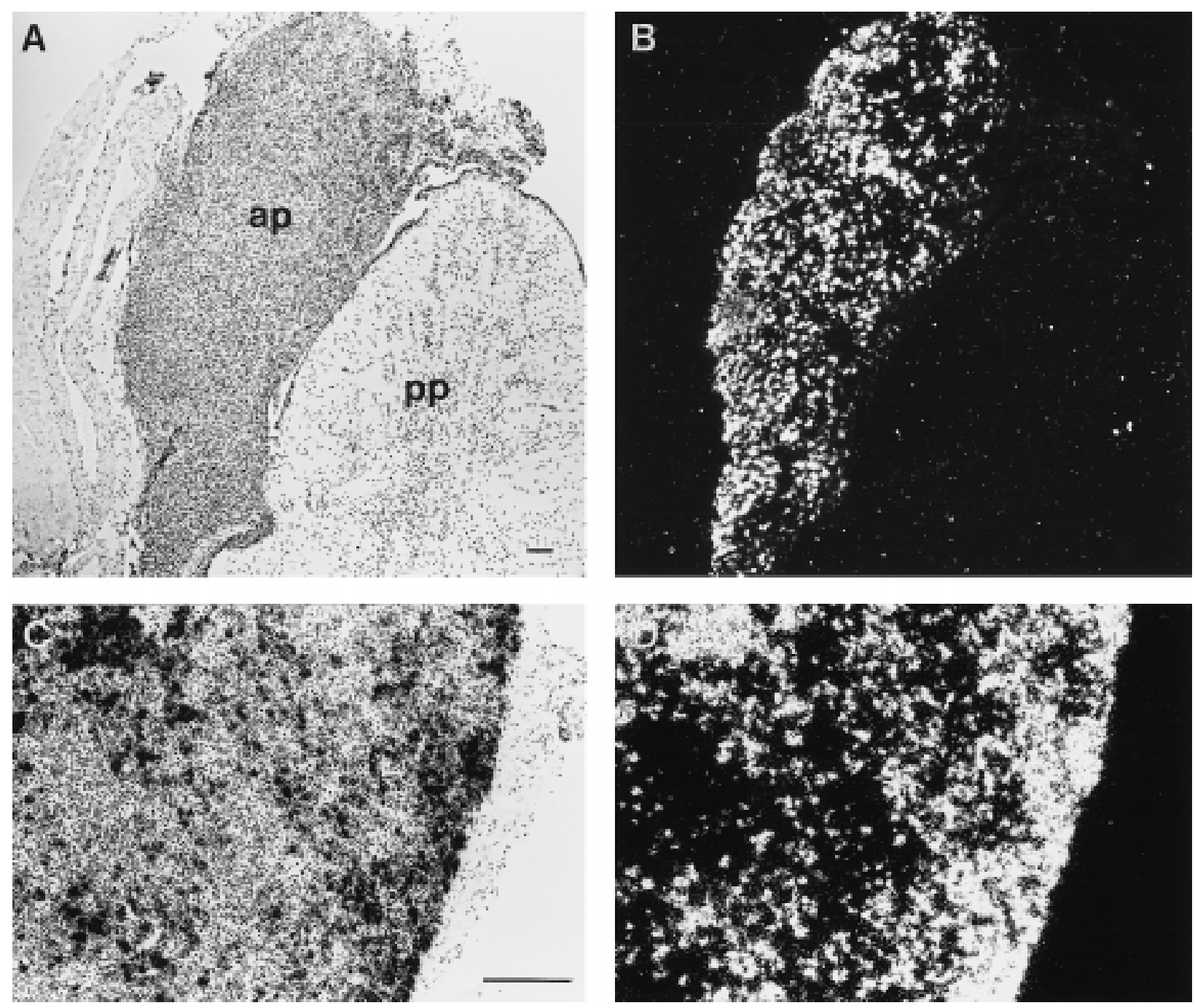

FIGURE 4. In situ hybridization of adult possum pituitary sections with a radioactively labelled possum gonadotrophin $\alpha$-subunit antisense riboprobe corresponding to nucleotides 181-719 of Fig. 1. A,C, bright-field photomicrographs; $\mathrm{B}, \mathrm{D}$, dark-field photomicrographs. Gonadotrophin $\alpha$-subunit gene expressing cells were identified throughout the anterior pituitary, though at higher density towards the periphery (C,D). No $\alpha$-subunit mRNA was detected in cells of the posterior pituitary. A,B, $35 \times$ magnification; C,D, $125 \times$ magnification; bar $=100 \mu \mathrm{m}$. ap, anterior pituitary; $\mathrm{pp}$, posterior pituitary.

et al. 1995). In those species examined, glycosylation of the gonadotrophin $\alpha$-subunit is not essential for receptor binding, but is required for maximal activation of the secondary messenger pathway and biological activity (Sairam 1989, Bishop et al. 1994, Nagaya \& Jameson 1994). Furthermore, variation of the terminal residues of the carbohydrate moieties, including sulphation, may modulate hormonal bioactivity by influencing such parameters as receptor binding affinity, secondary messenger activation and metabolic clearance rate (Wilson et al. 1990, Ulloa-Aguirre et al. 1995, Arey et al. 1997).
The presence of ten evolutionarily conserved cysteines in the possum gonadotrophin $\alpha$-subunit sequence, potentially forming five intramolecular disulphide bonds, indicated that the secondary structure of possum $\alpha$-subunit resembles that of eutherian $\alpha$-subunits (Pierce \& Parsons 1981, Combarnous 1992). Amino acids at the $C$-terminus of the $\alpha$-subunit, positions +75 to +96 , are thought to be of particular significance in the interaction of gonadotrophin hormones with their receptors (Combarnous 1992, Yoo et al. 1993) and within this region possum gonadotrophin $\alpha$-subunit conforms 
possum

ovine

bovine

porcine

horse
$\Delta \mathrm{G}$

(kcal/mole)

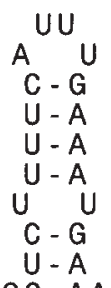

5 ' UGGC AAAA3'

$$
\begin{gathered}
U U \\
A \quad U \\
C-G \\
U-G \\
U-A \\
U-A \\
U U \\
C-G \\
U-A
\end{gathered}
$$$$
5 \text { 'UUGA AAUA3' }
$$
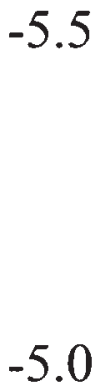

UU

A $U$

$U-G$

$U-A$

$U-A$

$U$ U

C - G

$U-A$

$U-A$

5 ' CUAG-UACA $3^{\prime}$

$U U$
$A U$
$C-G$
$U-G$
$U-A$
$U-A$
$U-U$
$C-G$
$U-A$

5 ' UUGA AAUA3 '

UU

A $U$

$U-G$

$U-A$

$U-A$

U C

C - G

$U-A$

5 'UCGC AAUG3'

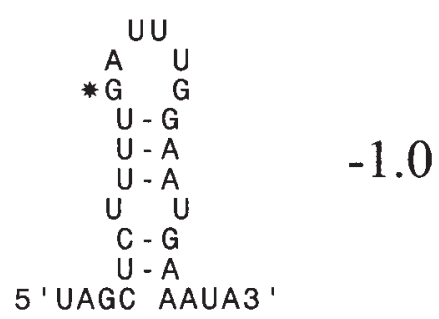

to the mammalian consensus, with the human and donkey sequences showing the greatest deviation from the consensus. The only amino acid residue unique to the possum gonadotrophin $\alpha$-subunit protein sequence was the valine at position +25 . However this is a conservative difference, with the mouse, rat, rabbit, porcine, equine and whale sequences all having a leucine at the equivalent position (Combarnous 1992). Consistent with the high level of homology between the possum and eutherian $\alpha$-subunit amino acid sequences was the finding that possum FSH can bind to both bovine and recombinant human FSH receptors (Moore et al. 1997).

Outside the coding region the possum gonadotrophin $\alpha$-subunit cDNA sequence had standard features characteristic of eukaryotic mRNAs. The sequence surrounding the translation start codon 5'-AGAGCCATGG-3' (nucleotides 112-121), resembled the vertebrate translation initiation consensus sequence, 5'-GCC(A/G)CCATGG-3' (Kozak 1987), and a polyadenylation sequence, 5'-AATAAA-3', was present (nucleotides 719-724) fourteen bases $5^{\prime}$ to the polyA tail (Proudfoot 1990).

Sequence homology between possum and eutherian $\alpha$-subunit transcripts extended into the $3^{\prime}$ UTR. Such sequence conservation between mammalian gonadotrophin $\alpha$-subunit $3^{\prime}$ UTRs has been noted previously (Nilson et al. 1983, Hirai et al. 1989). Two overlapping imperfect palindromic sequences, nucleotides 658-675 and nucleotides 660-678, present in the possum $\alpha$-subunit $3^{\prime}$ UTR could potentially form hairpin loops in the mRNA transcripts with predicted free energies of formation $(\Delta \mathrm{G})$ of $-5 \cdot 5$ and $-5.4 \mathrm{kcal} / \mathrm{mol}$ respectively, as calculated using the RNA folding computer program mfold (Fig. 5) (Walter et al. 1994). Comparison of the 3' UTR sequences of the possum, ovine, human, bovine and porcine $\alpha$-subunit mRNAs indicated that the imperfect palindrome formed by

FIGURE 5. Potential hair-pin loop secondary structures formed by a conserved 18-20 nucleotide sequence present in the $3^{\prime}$ UTR of mammalian gonadotrophin $\alpha$-subunit mRNA sequences: possum (nucleotides 654-678, Fig. 1), ovine (nucleotides 616-641, Bello et al. 1989), human (nucleotides 583-610, Fiddes \& Goodman 1979), bovine (nucleotides 623-648, Erwin et al. 1983), porcine (nucleotides 630-655, Hirai et al. 1989) and horse (nucleotides 494-518, Stewart et al. 1987). The base-pairing alignments and theoretical Gibbs free energy $(\Delta G)$ values were calculated using the computer program mfold (Walter et al. 1994, http://www.ibc.wustl.edu/ zuker/mfold/). The $\Delta \mathrm{G}$ value of the horse $3^{\prime}$ UTR potential hairpin is less favourable than the others due to a $G$ (asterisk), rather than a $\mathrm{C}$, in the stem portion of the hairpin. 
nucleotides $658-675$ is evolutionarily conserved and that similar hairpin secondary structures could potentially form in all five transcripts (Figs 3 and 5). However, the potential hairpin loop sequence was not present in all reported mammalian $\alpha$-subunit mRNA sequences; a $G$ in the horse $3^{\prime}$ UTR removes a potential base pair in the hairpin stem reducing the predicted $\Delta \mathrm{G}$ value to $-1.0 \mathrm{kcal} / \mathrm{mol}$, while the rat and mouse transcripts entirely lack the sequence (Chin et al. 1981, Godine et al. 1982). Conservation of mRNA secondary structure may indicate functional significance, and a role for hairpin loop structures in regulating mRNA stability in some transcripts is well established (Rajagopalan \& Malter 1997). It is noteworthy that the position of the possum $\alpha$-subunit putative hairpin loop with respect to the translation termination codon was also conserved, varying between 177 and 188 nucleotides in the six $\alpha$-subunit $3^{\prime}$ UTR sequences shown in Fig. 3 . Furthermore, in five of the six $3^{\prime}$ UTR sequences in Fig. 3, the putative hairpin sequence was located six or eight nucleotides $5^{\prime}$ to the sequence AUUUA (AUUUUA in horse) which itself was positioned approximately 30 nucleotides $5^{\prime}$ to the polyadenylation signal AAUAAA. In contrast the human $3^{\prime}$ UTR sequence had 15 nucleotides separating the sequence AUUAA and the polyA tail. A role for such AU-rich elements (AREs) in influencing mRNA stability has been proposed (Shaw \& Kamen 1986, Sachs 1993), with recent work indicating that the AUUUA sequence may form a necessary but not sufficient core sequence that destabilizes some mRNAs (Zubiaga et al. 1995, Lagnado et al. 1994). It has been noted previously that the prevalence of $(\mathrm{U})_{\mathrm{n}} \mathrm{A}$ sequences, a possible indicator of mRNA stability, suggested that the porcine, human, bovine and equine gonadotrophin $\alpha$-subunit transcripts may be less stable than those of rat and mouse (Wreschner \& Rechavi 1988, Hirai et al. 1989).

The pattern of gonadotrophin $\alpha$-subunit gene expression in the adult possum pituitary was similar to that described previously for eutherian mammals, with in situ hybridization identifying a punctate distribution of cells in the anterior pituitary synthesizing $\alpha$-subunit mRNA. As the gonadotrophin $\alpha$-subunit is common to the hormones FSH, LH and TSH, the hybridizing cells are probably gonadotrophs, producing $\mathrm{FSH}$ and LH, and thyrotrophs, producing TSH.

In summary, a cDNA sequence of the possum gonadotrophin $\alpha$-subunit gene has been determined. The coding sequence showed a high level of homology, at both the nucleotide and predicted amino acid levels, with the gonadotrophin $\alpha$-subunit genes of eutherian mammals. From the perspective of designing possum biocontrol strategies, the high level of evolutionary conservation of the gonadotrophin $\alpha$-subunit amino acid sequence indicates that gonadotrophins may be unsatisfactory 'target molecules' as they offer little species specificity. A possible hairpin loop region within the possum gonadotrophin $\alpha$-subunit mRNA $3^{\prime}$ UTR has been described and the evolutionary conservation of this sequence indicates possible functional significance, perhaps influencing mRNA stability. Expression studies using the $\alpha$-subunit cDNA indicated close similarity with other mammals.

\section{ACKNOWLEDGEMENTS}

The authors thank Drs Douglas Eckery and Lloyd Moore for constructive criticism of this manuscript. Thanks to Dr Robert Hickson for assistance with sequence analysis, to Ruth Kiel and Alan Barkus for assistance with figure preparation and to Leanne Still for the preparation of histological sections. This work was financially supported by the New Zealand Ministry of Agriculture (Policy Division).

\section{REFERENCES}

Arey BJ, Stevis PE, Deecher DC, Shen ES, Frail DE, Negro-Vilar A \& Lopez FJ 1997 Induction of promiscuous $\mathrm{G}$ protein coupling of the follicle-stimulating hormone (FSH) receptor: a novel mechanism for transducing pleiotropic actions of FSH isoforms. Molecular Endocrinology 11 517-526.

Bello PA, Mountford PS, Brandon MR \& Adams TE 1989 Cloning and DNA sequence analysis of the cDNA for the common $\alpha$-subunit of the ovine pituitary glycoprotein hormones. Nucleic Acids Research 1710494.

Bishop LA, Robertson DM, Cahir N \& Schofield PR 1994 Specific roles of the asparagine-linked carbohydrate residues of recombinant human follicle stimulating hormone in receptor binding and signal transduction. Molecular Endocrinology 8 722-731.

Burbidge AA \& McKenzie NL 1989 Patterns in the modern decline of Western Australia's vertebrate fauna: causes and conservation implications. Biological Conservation $\mathbf{5 0}$ 143-198.

Chin WW, Kronenberg HM, Dee PC, Maloof F \& Habener JF 1981 Nucleotide sequence of the mRNA encoding the pre- $\alpha$-subunit of mouse thyrotropin. Proceedings of the National Academy of Sciences of the USA 78 5329-5333.

Chomczynski P \& Saachi N 1987 Single-step method of RNA isolation by acid guanidinium thiocyanate-phenolchloroform extraction. Analytical Biochemistry 162 156-159.

Chopineau M \& Stewart F 1996 Cloning and analysis of the cDNA for the common $\alpha$-subunit of the donkey pituitary glycoprotein hormones. Fournal of Molecular Endocrinology $169-13$

Combarnous Y 1992 Molecular basis of the specificity of binding of glycoprotein hormones to their receptors. Endocrine Reviews 13 670-691.

Cowan PE 1996 Possum biocontrol: prospects for fertility regulation. Reproduction, Fertility and Development $\mathbf{8}$ 655-660. 
Cowan PE \& Tyndale-Biscoe CH 1997 Australian and New Zealand mammal species considered to be pests or problems. Reproduction, Fertility and Development 9 27-36.

Erwin CR, Croyle ML, Donelson JE \& Maurer RA 1983 Nucleotide sequence of cloned complementary deoxyribonucleic acid for the $\alpha$ subunit of bovine pituitary glycoprotein hormones. Biochemistry 22 4856-4860.

Fiddes JC \& Goodman HM 1979 Isolation, cloning and sequence analysis of the cDNA for the $\alpha$-subunit of human chorionic gonadotropin. Nature 281 351-356.

Fiddes JC \& Goodman HM 1981 The gene encoding the common alpha subunit of the four human glycoprotein hormones. Fournal of Molecular and Applied Genetics 1 3-18.

Frohman MA, Dush MK \& Martin GR 1988 Rapid amplification of full-length cDNAs from rare transcripts: amplification using a single gene-specific oligonucleotide primer. Proceedings of the National Academy of Sciences of the USA 85 8998-9002.

Godine JE, Chin WW \& Habener $1982 \alpha$-Subunit of rat pituitary glycoprotein hormones. Primary structure of the precursor determined from the nucleotide sequence of cloned cDNAs. Fournal of Biological Chemistry 257 8368-8371.

Hanahan D 1985 Techniques for transformation of E. coli. In DNA Cloning Volume I, pp 109-135. Ed DM Glover. Oxford: IRL Press.

Hirai T, Takikawa H \& Kato Y 1989 Molecular cloning of cDNAs for precursors of porcine pituitary glycoprotein hormone common $\alpha$-subunit and of thyroid stimulating hormone $\beta$-subunit. Molecular and Cellular Endocrinology 63 208-217.

Hsueh AJW, Bicsak TA, Jia X, Dahl KD, Fauser BCJM, Galway AB, Czekala N, Pavlou SN, Papkoff H, Keene J \& Boime I 1989 Granulosa cells as hormone targets: the role of biologically active follicle-stimulating hormone in reproduction. Recent Progress in Hormone Research $\mathbf{4 5}$ 209-277.

Janke A, Xu X \& Arnason U 1997 The complete mitochondrial genome of the wallaroo (Macropus robustus) and the phylogenetic relationship among Monotremata, Marsupialia, and Eutheria. Proceedings of the National Academy of Sciences of the USA 94 1276-1281.

Kendall SK, Samuelson LC, Saunders TL, Wood RI \& Camper SA 1995 Targeted disruption of the pituitary glycoprotein hormone $\alpha$-subunit produces hypogonadal and hypothyroid mice. Genes and Development 9 2007-2019.

Kozak M 1987 An analysis of 5'-noncoding sequences from 699 vertebrate messenger RNAs. Nucleic Acids Research 15 8125-8148.

Kumar TR, Wang Y, Lu N \& Matzuk MM 1997 Follicle stimulating hormone is required for ovarian follicle maturation but not male fertility. Nature Genetics 15 201-204.

Lagnado CA, Brown CY \& Goodall GJ 1994 AUUUA is not sufficient to promote poly(A) shortening and degradation of an mRNA: the functional sequence within AU-rich elements may be UUAUUUA(U/A)(U/A). Molecular and Cellular Biology 14 7984-7995.

Low BS 1978 Environmental uncertainty and the placental strategies of marsupials and placentals. American Naturalist 112 197-213.

Mengeling BJ, Manzella SM \& Baenziger JU 1995 A cluster of basic amino acids within an $\alpha$-helix is essential for $\alpha$-subunit recognition by the glycoprotein hormone $N$-acetylgalactosaminyltransferase. Proceedings of the National Academy of Sciences of the USA 92 502-506.

Moore LG, Ng-Chie W, Lun S, Lawrence SB, Young W \& McNatty KP 1997 Follicle-stimulating hormone in brushtail possum (Trichosurus vulpecula): purification, characterization, and radioimmunoassay. General and Comparative Endocrinology 106 30-38.

Nagaya T \& Jameson JL 1994 Structural features of the glycoprotein hormones genes and their encoded proteins. In The Pituitary Gland, pp 63-89. Ed H Imura. New York: Raven Press.

Nilson JH, Thomason AR, Cserbak MT, Moncman CL \& Woychik RP 1983 Nucleotide sequence of a cDNA for the common $\alpha$ subunit of the bovine pituitary glycoprotein hormones. Fournal of Biological Chemistry 258 4679-4682.

Pierce JG \& Parsons TF 1981 Glycoprotein hormones: structure and function. Annual Review of Biochemistry 50 465-495.

Pless DD \& Lennarz WJ 1977 Enzymatic conversion of proteins to glycoproteins. Proceedings of the National Academy of Sciences of the USA 74 134-138.

Proudfoot N 1990 Poly(A) signals. Cell 64 671-674.

Rajagopalan LE \& Malter JS 1997 Regulation of eukaryotic messenger RNA turnover. Progress in Nucleic Acid Research and Molecular Biology 56 257-286.

Richards JS 1994 Hormonal control of gene expression in the ovary. Endocrine Reviews 15 725-751.

Ryan RJ, Keutmann HT, Charlesworth MC, McCormick DJ, Milius RP, Calvo FO \& Vutyavanich T 1987 Structurefunction relationships of gonadotropins. Recent Progress in Hormone Research 43 383-429.

Sachs AB 1993 Messenger RNA degradation in eukaryotes. Cell 74 413-421.

Sairam MR 1989 Role of carbohydrates in glycoprotein hormone signal transduction. FASEB Fournal 3 1915-1926.

Shaw G \& Kamen R 1986 A conserved AU sequence from the $3^{\prime}$ untranslated region of GM-CSF mRNA mediates selective mRNA degradation. Cell 46 659-667.

Stewart F, Thomson JA, Leigh SEA \& Warwick KM 1987 Nucleotide (cDNA) sequence encoding the horse gonadotrophin $\alpha$-subunit. Fournal of Endocrinology 115 341-346.

Tisdall DJ, Hudson N, Smith P \& McNatty KP 1994 Localization of ovine follistatin and $\alpha$ and $\beta \alpha$ inhibin mRNA in the sheep ovary during the oestrous cycle. Fournal of Molecular Endocrinology 12 181-183.

Tyndale-Biscoe CH \& Janssens PA (Eds) 1988 The Developing Marsupial: Models for Biomedical Research. Berlin: Springer Verlag.

Ulloa-Aguirre A, Midgley AR Jr, Beitins IZ \& Padmanabhan V 1995 Follicle-stimulating isohormones: characterization and physiological relevance. Endocrine Reviews 16 765-787.

Walter AE, Turner DH, Kim J, Lyttle MH, Muller P, Mathews DH \& Zuker M 1994 Coaxial stacking of helixes enhances binding of oligoribonucleotides and improves predictions of RNA folding. Proceedings of the National Academy of Sciences of the USA 91 9218-9222.

Wilson CA, Leigh AJ \& Chapman AJ 1990 Gonadotrophin glycosylation and function. Fournal of Endocrinology 125 3-14.

Wreschner DH \& Rechavi G 1988 Differential mRNA stability to reticulocyte ribonucleases correlates with $3^{\prime}$ non-coding (U) ${ }_{n}$ A sequences. European Fournal of Biochemistry 172 333-340.

Yoo J, Zheng H, Ji I, Murdoch WJ \& Ji TH 1993 COOHterminal amino acids of the $\alpha$ subunit play common and different roles in human choriogonadotropin and follitropin. Fournal of Biological Chemistry 268 13034-13042.

Zubiaga AM, Belasco JG \& Greenberg ME 1995 The nonamer UUAUUUAUU is the key AU-rich sequence motif that mediates mRNA degradation. Molecular and Cellular Biology 15 2219-2230.

REVISED MANUSCRIPT RECEIVED 17 November 1997 